12. K. Yosida, On Titchmarsh-Kodaira's formula concerning Weyl-Stone's eigenfunction expansion, Nagoya Math. J. (June) vol. 1 (1950) pp. 49-58. 188.

13. — Correction to my paper [9], Nagoya Math. J. (October vol. 6 (1953) pp. 187-

14. S. Karlin and J. McGregor, Representation of a class of stochastic processes, Proc. Nat. Acad. U.S.A. (6) vol. 41 (1955) pp. 387-391.ii i

15. W. Ledermann and G. Reuter, Spectral theory for the differential equations of simple birth and death processes, Philos. Trans. Roy. Soc. London. Ser. A. vol. 246 (1954) pp. 321-369.

16. W. Feller, The parabolic differential equations and the associated semi-groups of transformations, Ann. of Math. (3) vol. 55 (1952) pp. 468-519.

17. E. Hille, Functional analysis and semi-groups, Amer. Math. Soc. Colloquium Publications, vol. 31, New York, 1948.

18. R. Courant and D. Hilbert, Methoden der mathematischen Physik, vol. 1, Berlin, Springer, 1931.

19. D. V. Widder, The Laplace transform, Princeton University Press, 1946.

20. A. N. Kolmogorov, Über die analytischen Methoden in der Wahrscheinlichkeitsrechnung, Math. Ann. vol. 104 (1931) pp. 415-458.

21. A. Khinchin, Asymptotische Gesetze der Wahrscheinlichkeitsrechnung, Ergebnisse der Mathematik u. ihrer Grenzgebiete, vol. 2(4), New York, Chelsea, 1948.

Princeton University, PRINCETON, N. J.

\title{
ERRATA, VOLUME 79
}

Monotone and convex operator functions. By J. Bendat and S. Sherman. Pages 58-71.

Page 69, lines 1-2. Delete "linear." Add " $+f^{\prime \prime}\left(x_{0}\right)\left(x-x_{0}\right)^{2} . "$ 